\title{
Factor IX Inactivation
}

National Cancer Institute

\section{Source}

National Cancer Institute. Factor IX Inactivation. NCI Thesaurus. Code C131663.

Presence of inactivating antibodies to factor IX in the blood. 